\title{
On the thermodynamic aspect of zinc oxide polymorphism. Calorimetric study of metastable rock salt $\mathrm{ZnO}$
}

\author{
Felix Yu. Sharikov, ${ }^{1}$ Petr S. Sokolov, ${ }^{2}$ Andrey N. Baranov, ${ }^{3, *}$ Vladimir L. Solozhenko ${ }^{2, *}$ \\ ${ }^{1}$ University of Mines, St. Petersburg, 199106, Russia \\ 2 LSPM-CNRS, Université Paris Nord, 93430 Villetaneuse, France \\ ${ }^{3}$ Moscow State University, Chemistry Department, Moscow, 119991, Russia
}

Keywords: zinc oxide; solution calorimetry; phase transition; enthalpy

\begin{abstract}
The enthalpies of dissolution of metastable rock salt $(r s)$ and thermodynamically stable wurtzite $(w)$ polymorphs of zinc oxide in aqueous $\mathrm{H}_{2} \mathrm{SO}_{4}$ have been measured in direct calorimetric experiments at $303 \mathrm{~K}$ and $0.1 \mathrm{MPa}$ and the obtained results enabled determination of the standard enthalpy of the rock salt-to-wurtzite phase transition in $\mathrm{ZnO}, \Delta_{\mathrm{tr}} \mathrm{H}=-11.7 \pm 0.3 \mathrm{~kJ} / \mathrm{mol}$.
\end{abstract}

\section{Introduction}

Since the discovery of high-pressure polymorph of zinc oxide, rock salt $\mathrm{ZnO}$ in 1962 [1], its synthesis and properties have been intensively studied [2-14]. The most of these studies were conducted in situ under high pressure due to the problems with $r s-\mathrm{ZnO}$ recovery at ambient conditions.

Leitner et al. [2] have tried to extract the thermodynamic data of rock salt $\mathrm{ZnO}$ from ab initio simulations and experimental data on the pressure-induced wurtzite-to-rock salt phase transition in $\mathrm{ZnO}$ available in the literature. However, neglecting the strongly pronounced kinetic features of this transition below $1000 \mathrm{~K}$ [8] rendered these data ambiguous [3]. As a result, a completely incorrect set of thermodynamic functions of $r s-\mathrm{ZnO}$ still prevails in the literature.

Recently, it was found that single-phase $r s-\mathrm{ZnO}$ synthesized at $7.7 \mathrm{GPa}$ and $800 \mathrm{~K}$ can be completely recovered at normal conditions in the form of macroscopic $\left(>100 \mathrm{~mm}^{3}\right)$ bulks [10]. At ambient pressure these bulks are kinetically stable up to $370 \mathrm{~K}$ which allows the direct measuring of thermochemical properties of metastable $r s-\mathrm{ZnO}$ by conventional calorimetry. In the present work, enthalpies of dissolution of two $\mathrm{ZnO}$ polymorphs in aqueous $\mathrm{H}_{2} \mathrm{SO}_{4}$ were measured by solution calorimetry at ambient conditions.

\footnotetext{
*Corresponding authors: anb@inorg.chem.msu.ru \& vladimir.solozhenko@univ-paris13.fr
} 


\section{Experimental}

Single-phase nanocrystalline bulk $r s-\mathrm{ZnO}$ has been synthesized from $w$ - $\mathrm{ZnO}$ nanopowder at $7.7 \mathrm{GPa}$ and $800 \mathrm{~K}$ with subsequent rapid quenching. The details of high-pressure synthesis and characterization of recovered samples have been described elsewhere [10]. Nanocrystalline bulk $w-\mathrm{ZnO}$ to be used as a reference sample was produced by a reverse phase transition of nanocrystalline bulk $r s-\mathrm{ZnO}$ as a result of heating from 300 to $523 \mathrm{~K}$ with heating rate of $1^{\circ} \mathrm{K} / \mathrm{min}$ with DSC monitoring of the transition. This approach was used to eliminate possible influence of grain-size and surface contribution on heat effects as the "secondary" bulk $w$ - $\mathrm{ZnO}$ should inherit the whole prehistory of starting $r s-\mathrm{ZnO}$, except for crystal structure. Phase purity of all samples was confirmed by powder $\mathrm{X}$-ray diffraction.

A Calvet calorimeter (SETARAM C80) operated in isothermal and linear scanning modes was used. Heat flow calibration of the instrument was done using the EJ3 calibration unit and Joule effect calibration cells (SETARAM S60/1434) and checked with the melting enthalpy of indium.

Isothermal experiments have been performed at $302.75 \mathrm{~K}$. 2-cell calorimetric vessels made of stainless steel with Teflon membranes were used. Mixing was performed by reversing the calorimetric block. $2 \mathrm{~N} \mathrm{H}_{2} \mathrm{SO}_{4}$ was prepared from $95 \% \mathrm{H}_{2} \mathrm{SO}_{4}$ and deionized water. Initial and final concentrations of $\mathrm{H}_{2} \mathrm{SO}_{4}$ were checked by DMA 35 Ex Anton Paar density meter. Bulk $\mathrm{ZnO}$ (from 3 to $20 \mathrm{mg}$, with $\pm 0.01 \mathrm{mg}$ accuracy, see Table 1) were dissolved in $2.0 \mathrm{~mL}$ (with $\pm 0.1 \mathrm{mg}$ weight monitoring) of $2 \mathrm{~N}$ $\mathrm{H}_{2} \mathrm{SO}_{4}$ under strictly isothermal conditions $( \pm 0.01 \mathrm{~K})$, and the heat production rate was measured. The experimental data were processed using Calisto (AKTS AG) and TDPro (CISP Ltd) software packages.

\section{Results and Discussion}

The following reactions occur in the calorimetric vessel at $302.75 \mathrm{~K}$ after piercing the membrane between the two cells and mixing the components:

$$
\begin{aligned}
& r s-\mathrm{ZnO} \text { (nanocrystalline) }+\mathrm{H}_{2} \mathrm{SO}_{4}(\mathrm{aq}) \rightarrow \mathrm{Zn}^{2+}+\mathrm{SO}_{4}{ }^{2-}+\mathrm{H}_{2} \mathrm{O} \text { (solution) }+\Delta \mathrm{H}_{1} \\
& w-\mathrm{ZnO} \text { (nanocrystalline) }+\mathrm{H}_{2} \mathrm{SO}_{4}(\mathrm{aq}) \rightarrow \mathrm{Zn}^{2+}+\mathrm{SO}_{4}{ }^{2-}+\mathrm{H}_{2} \mathrm{O}(\text { solution})+\Delta \mathrm{H}_{2}
\end{aligned}
$$

Experimental heat flow curves of dissolution of nanocrystalline $r s-\mathrm{ZnO}$ and $w-\mathrm{ZnO}$ bulks are shown in Fig. 1 . The enthalpy values measured in calorimetric runs \#(1) and \#(2) are $\Delta H_{1}$ and $\Delta H_{2}$ (see Table 1). In both cases the final state is the same, i.e. $\mathrm{ZnSO}_{4}$ solution in aqueous $\mathrm{H}_{2} \mathrm{SO}_{4}$. Since the real structure and impurity content for both $r s-\mathrm{ZnO}$ and $w-\mathrm{ZnO}$ samples are almost the same, one can conclude that the $\left(\Delta \mathrm{H}_{1}-\Delta \mathrm{H}_{2}\right)$ value corresponds to the enthalpy of phase transition between two $\mathrm{ZnO}$ polymorphs i.e. to the $r s-\mathrm{ZnO}$-to- $w$ - $\mathrm{ZnO}$ transition enthalpy $\left(\Delta_{\mathrm{tr}} \mathrm{H}\right)$ at $302.75 \mathrm{~K}$.

The $\Delta_{\mathrm{tr}} \mathrm{H}^{0}$ value of $-11.7 \pm 0.3 \mathrm{~kJ} /$ mole determined by solution calorimetry also may include some strain energy that is usual for bulk samples quenched from high pressure - high temperature conditions. 
However, this contribution should not exceed $-0.1 \mathrm{~kJ} /$ mole similar to those for ball-milling nanocrystalline silicon [15] and cold rolling nanocrystalline copper [16].

We have also conducted calorimetric study of the solid-state $r s-\mathrm{ZnO}$-to- $w$ - $\mathrm{ZnO}$ transition in a linear scanning mode at heating rate of $1.0 \mathrm{~K} / \mathrm{min}$ in the $300-500 \mathrm{~K}$ temperature range. The resulting heat flow curve is presented in Fig. 2. The obtained transition enthalpy of $-12.0 \pm 0.2 \mathrm{~kJ} / \mathrm{mole}$ is in excellent agreement with the corresponding value from our isothermal experiments. Thus, two independent calorimetric techniques used in the present work gave very close values for the $r s-\mathrm{ZnO}$-to- $w$ - $\mathrm{ZnO}$ transition enthalpy.

In the earlier work of Leitner et al. [2], the key thermodynamic value, $\Delta_{\mathrm{tr}} G^{0}=23.12 \mathrm{~kJ} / \mathrm{mole}$, corresponding to the wurtzite-to-rock-salt phase transition in $\mathrm{ZnO}$ at $0.1 \mathrm{MPa}$ and $298.15 \mathrm{~K}$, has been estimated exclusively from one of the most questionable values, the room-temperature equilibrium transition pressure, $P_{\text {tr }}$. The choice of $P_{\mathrm{tr}}=9.6 \mathrm{GPa}$ based on averaging of $a b$ initio estimations (that vary from $7.4 \mathrm{GPa}$ [12] to $12.7 \mathrm{GPa}$ [13]) and one randomly chosen value of the onset pressure of kinetically hindered phase transition at $300 \mathrm{~K}$ (that also varies from 7.5 GPa [7] to 10.0 GPa [14]). All this leads to completely wrong equilibrium $P-T$ line in the high pressure - high temperature region, where the transition is governed by thermodynamics, and equilibrium experimental data are available $[6,7]$.

The standard enthalpy of the $w$-ZnO-to-rs- $\mathrm{ZnO}$ phase transition, $\Delta_{\mathrm{tr}} \mathrm{H}^{0}(298.15 \mathrm{~K})=11.7 \pm 0.3 \mathrm{~kJ} / \mathrm{mole}$ derived from our experimental results is two times lower than the "recommended" value, $\Delta_{\mathrm{tr}} \mathrm{H}^{0}(298.15 \mathrm{~K})=23.93 \pm 3.11 \mathrm{~kJ} /$ mole claimed by Leitner et al. [2] under unfounded suggestion that $P_{\text {tr }}=9.6 \mathrm{GPa}$. Indeed, it is known that wurtzite $\mathrm{ZnO}$ starts to transform into $r s-\mathrm{ZnO}$ already at pressures above $5 \mathrm{GPa}$ [6-8]. At room temperature this transition is very sluggish due to the existence of a strong kinetic barrier, which hinders the nucleation of a new phase [8]. The transition pressure depends on temperature and shows a substantial (from 9 to $2 \mathrm{GPa}$ at room temperature) hysteresis $[6,7]$. The hysteresis loop decreases with the temperature increase, and above $1000 \mathrm{~K}$ the branches of direct and reverse transitions merge at pressure of about $5.8 \mathrm{GPa}$, which can be considered as the equilibrium pressure of this phase transition. With more reasonable choice of the $300-\mathrm{K}$ transition pressure i.e. $P_{\text {tr }} \approx 5.8 \mathrm{GPa}$, the $\Delta_{\mathrm{tr}} \mathrm{H}^{0}$ value should be about $14 \mathrm{~kJ} / \mathrm{mole}$, in agreement with the experimental value of transition enthalpy found in the present work.

\section{Acknowledgments}

We thank Dr. O.O. Kurakevych for valuable discussion. ANB is grateful to the Université Sorbonne Paris Cité for financial support. 


\section{References}

1. C. Bates, W. White, R. Roy, Science, 137 (1962) 993.

2. J. Leitner, M. Kamrádek, D. Sedmidubský, Thermochim. Acta, 572 (2013) 1.

3. P.S. Sokolov, O.O. Kurakevych, A.N. Baranov, V.L. Solozhenko, Comment on "Thermodynamic properties of rock-salt ZnO", Arxiv.org/abs/1311.0770

4. P. Davies and A. Navrotsky, J. Solid State Chem., 38 (1981) 264.

5. A.A. Politov, B.A. Fursenko, I.Yu. Prosanov, S.V. Mytnichenko, V.V. Boldyrev, Doklady Akademii Nauk SSSR, 334 (1994) 194.

6. K. Kusaba, Y. Syono, T. Kikegawa, Proc. Jpn Acad., 75 (1999) 1.

7. F. Decremps, J. Zhang, R. Liebermann, Europhys. Lett., 51 (2000) 268.

8. V.L. Solozhenko, O.O. Kurakevych, P.S. Sokolov, A.N. Baranov, J. Phys. Chem. A, 115 (2011) 4354.

9. P.S. Sokolov, A.N. Baranov, Zh.V. Dobrokhotova, V.L. Solozhenko, Russ. Chem. Bull., 59 (2010) 325.

10. A.N. Baranov, P.S. Sokolov, V.A. Tafeenko, C. Lathe, Y.V. Zubavichus, A.A. Veligzhanin, M V. Chukichev, V.L. Solozhenko, Chem. Mater., 25 (2013) 1775.

11. P.S. Sokolov, A.N. Baranov, A.M.T. Bell, V.L. Solozhenko, Solid State Comm., 177 (2014) 65.

12. A. Seko, F. Oba, A. Kuwabara,I. Tanaka, Phys. Rev. B, 72 (2005) 024107.

13. M. Kalay, H.H. Kart, S Özdemir Kart, T Çağin, J. Alloys Compd., 484 (2009) 306.

14. L. Gerward, J. S. Olsen, J. Synchrotron Rad., 2 (1995) 233.

15. E. Gaffet,M. Harmelin, J. Less.-Comm. Metals., 157 (1990) 201.

16. L. Lu, N.R. Tao, L.B. Wang, B.Z. Ding, K. Lu, J. Appl. Phys., 89 (2001) 6408. 
Table 1. Calorimetric results for the dissolution of nanocrystalline $\mathrm{ZnO}$ bulks in $2 \mathrm{~N}_{2} \mathrm{SO}_{4}$ at $302.75 \mathrm{~K}$

\begin{tabular}{|c|c|c|c|c|c|}
\hline \multirow{2}{*}{ Run \# } & \multicolumn{2}{|c|}{$r s-\mathrm{ZnO}$} & \multicolumn{2}{c|}{$w-\mathrm{ZnO}$} & \multirow{2}{*}{$\Delta_{\text {tr }} \mathrm{H}(\mathrm{kJ} / \mathrm{mole})$} \\
\cline { 2 - 5 } & $\mathrm{m}(\mathrm{mg})$ & $\Delta \mathrm{H}_{1}(\mathrm{~J} / \mathrm{g})$ & $\mathrm{m}(\mathrm{mg})$ & $\Delta \mathrm{H}_{2}(\mathrm{~J} / \mathrm{g})$ & \\
\hline 1 & 19.64 & -1291.6 & 15.76 & -1150.9 & -11.5 \\
\hline 2 & 6.59 & -1320.5 & 6.55 & -1184.4 & -11.1 \\
\hline 3 & 2.58 & -1325.6 & 4.17 & -1171.8 & -12.5 \\
\hline
\end{tabular}




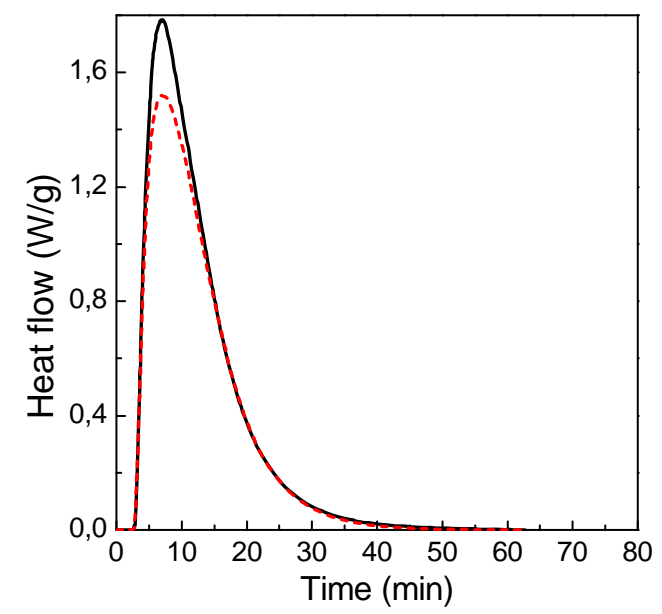

Figure 1. Heat flow curves of dissolution of nanocrystalline zinc oxide in $2 \mathrm{~N} \mathrm{H}_{2} \mathrm{SO}_{4}$ (Run 02 , see Table 1): bulk rs-ZnO (black solid line) and bulk $w$ - $\mathrm{ZnO}$ (red dashed line).

Temperature (K)

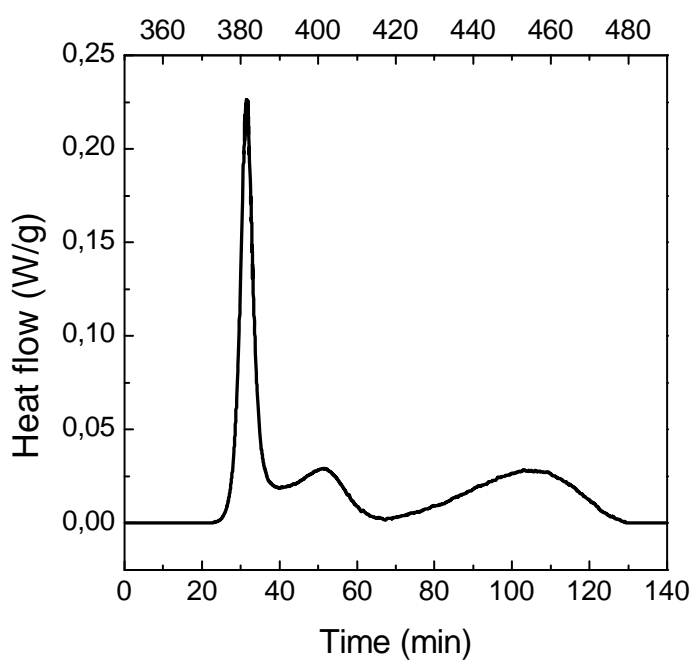

Figure 2. Heat flow curve of solid-state phase transition of nanocrystalline $r s-\mathrm{ZnO}$ bulk $(16.13 \mathrm{mg}$ ) into $\mathrm{w}-\mathrm{ZnO}$ under linear heating of $1.0 \mathrm{~K} / \mathrm{min}$. 